\title{
Industrial Hygiene in the United States-its History, Professional Organizations and Challenges
}

\section{G. X. Kortsha}

President of the American Industrial Hygiene Association

General Motors Corporation

DETROIT - U.S.A.

The history of the development of Industrial Hygiene, which started in 1914, is summarized by a series of relevant events. This development includes the formation of different professional organizations such as the American Conference of Governmental Industrial Hygienists, the American Industrial Hygiene Association, the American Academy of Industrial Hygiene, whose objectives and characteristics differ substantially.

Among the challenges facing the industrial hygiene profession, one is concerning the education and the training of students in this field. The multidisci- plinary aspect of industrial hygiene makes an advanced training in the specialized fields difficult. Another area of increasing concern is that of indoor air pollution as a consequence of the building of more energy efficient homes. The scope and functions of Industrial Hygiene has to be broadened to encompass these new areas of interest.

The basic responsabilities of Industrial hygiene in respect of labor, management and the Public at large are emphasized as well as the importance of earning the confidence and respect of all the concerned people.

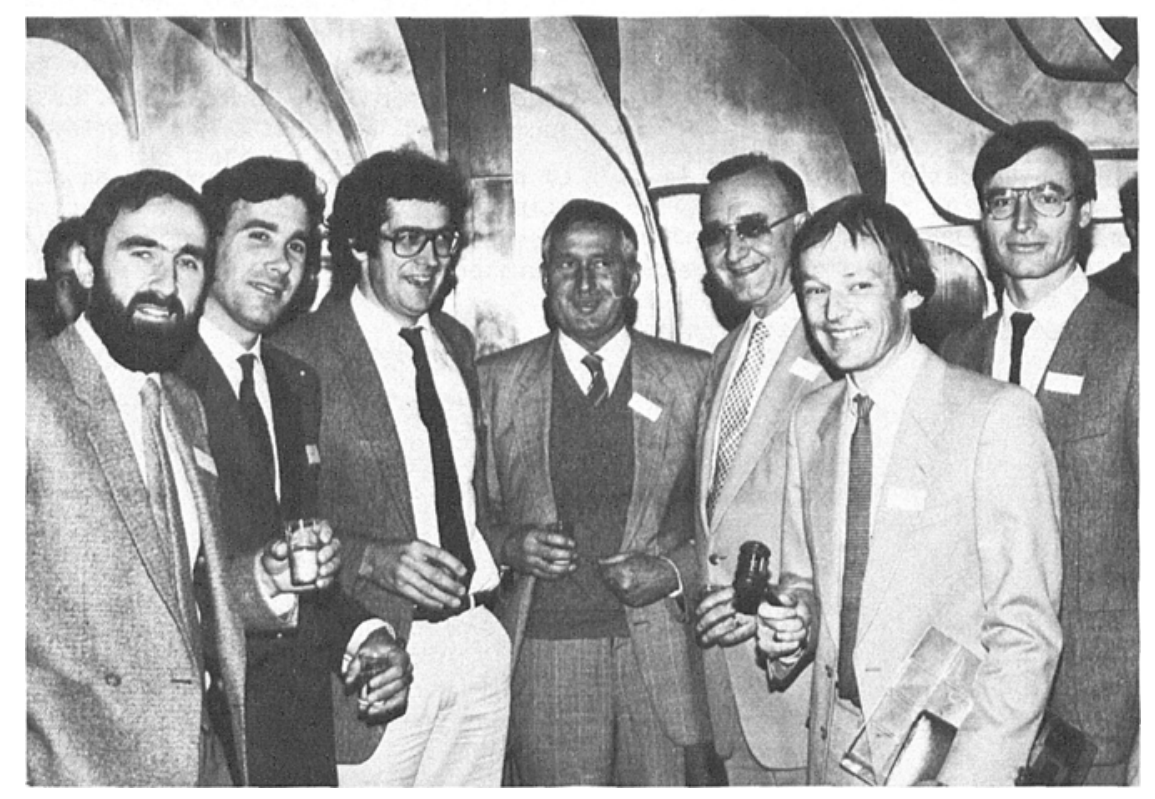

Six members of the new association in the company of G.X. Kortsha during the first meeting held on 2nd November 1984 at Neuchảtel 